\title{
Caring for Older Adults During Covid-19 Pandemic
}

\author{
Pamela Zimbeck ${ }^{1}$ and Sandeep Pagali ${ }^{2 *}$ \\ ${ }^{1}$ Department of Medicine, Division of Hospital Internal Medicine, Mayo Clinic, USA \\ ${ }^{2}$ Department of Medicine, Division of Geriatric Medicine and Gerontology, Mayo Clinic, USA \\ *Corresponding author: Sandeep Pagali, MD, MPH, Assistant Professor of Medicine, Mayo Clinic, Rochester MN, USA. \\ To Cite This Article: Zimbeck P, Pagali S. Caring for Older Adults During Covid-19 Pandemic. 2020 - 8(6). AJBSR.MS.ID.001338. D0I: 10.34297/ \\ AJBSR.2020.08.001338.
}

Received: 眥 May 05, 2020; Published: 菛 May 22, 2020

\section{Introduction}

SARS-Coronavirus-2 is leaving an indelible impression on the face of the world with a MASK. This invisible enemy has invaded our lives and robbed us of aspects of our lives that we thought were untouchable. Death, isolation, sickness, and fear now lurk in halls, homes and hearts. While we hope that many will recover from this viral infection, questions about how to do the right thing and even what is the right thing permeate our thoughts constantly. The scientific community and governments update management strategies frequently based on evolving data, all the time hoping for the best outcome. Suddenly, an organized and structured daily routine is filled with confusion and frustration. The days are riddled with constant changes and new instructions as we pray for strength, cures, and resilience. And behind this mask, our older adults who thrive on human connection suffer with the much needed measures and interventions of the hour, namely PHYSICAL DISTANCING.

Preliminary studies from Wuhan demonstrated that the high risk population for COVID-19 includes older adults in the community [1]. Therefore, we seek to protect the most vulnerable and isolate them from probable dangers or potential contaminants. As care providers, we fully understand the risk of older adults in the community during this pandemic. Older adults sit alone in their homes, their rooms, and their chairs. But are they truly safe? United States unfortunately leads the mortality metric for total COVID-19 related deaths across the globe as of date. Analysis revealed that 8 out of 10 of deaths reported in US are in older adults aged 65 and older; this is a huge number [2]. In efforts to prepare, preserve and protect during this pandemic, hospitalization for elective procedures and less emergent needs are deferred if possible. Face to face primary care provider appointments are discouraged unless absolutely necessary and many of the regular visits are converted to virtual visits. Social events and family gatherings with kids and grandkids are postponed to a later date. Even religious services are determined dangerous. To many of us, these changes are reasonable and make sense from a scientific perspective, but to the older adult who was raised in the knowledge that life is a braid made of family, faith and function, these protective measures reduce their happiness, distort their life and decrease satisfaction with their lives.

\begin{tabular}{|c|c|}
\hline Issue & Approach \\
\hline $\begin{array}{l}\text { Isolation from family - due to } \\
\text { physical distancing }\end{array}$ & $\begin{array}{l}\text { Facilitate video interactions (Facetime, } \\
\text { Zoom, Whatsapp). Help navigate } \\
\text { technology. }\end{array}$ \\
\hline $\begin{array}{l}\text { Decreased sensory perception } \\
\text { in the setting of PPE use (Face } \\
\text { mask, gown, eye shield) }\end{array}$ & $\begin{array}{l}\text { Provide auditory amplifiers, slow } \\
\text { down the conversation. }\end{array}$ \\
\hline $\begin{array}{l}\text { Limited common social } \\
\text { activities }\end{array}$ & $\begin{array}{c}\text { Encourage in-room board/card games, } \\
\text { crocheting/knitting, movies or album } \\
\text { review. }\end{array}$ \\
\hline Depression/Anxiety & $\begin{array}{l}\text { An optimistic perspective- science will } \\
\text { likely find some answers soon (or) this } \\
\text { would be a passing cloud like other } \\
\text { disasters that happened during their } \\
\text { lifetime. }\end{array}$ \\
\hline Frustration & $\begin{array}{l}\text { Empathetic reflection and sharing } \\
\text { hope }\end{array}$ \\
\hline
\end{tabular}

During pre-COVID time, when an older adult is admitted to the hospital, providers are watchful for complications as delirium, depression, anxiety, functional decline and behavioral changes. The doors to their rooms were open. They could see activity in the halls, and they had frequent visitors. They were encouraged to walk in the halls, play cards in the waiting room, or go to the chapel as part of the acute medical care facilitating their recovery. However, in the wake of the present SARS-Coronavirus-2 pandemic, the normal 
hospitalization is amalgamated with additional personal protective equipment (PPE) and physical distancing. Now, older adults sit in their rooms alone with no visitors. Health care providers limit their visits to one daily or maybe a video visit later in the day, seeking to reduce the exposure risk and minimizing PPE use given the projected shortage. Masks, gowns and gloves cover their care providers during these interactions. Smiles are hidden, voices are muffled. Doors are closed. This viral pandemic has changed the way we care for patients, and in our efforts to protect, we invite peril.

Isolation creates a substantial barrier to older adult care in the hospital as it is the little things that make a big difference: a touch, a smile, a comforting voice. Sensory perception is imperative to communication and building trust, especially in older adults. If the older adult already has hearing impairment, the muffled voice with the PPE of the provider makes it more challenging to hear. And if they read lips, all communication is invariably lost. Macular degeneration and vision loss are also more common in older adults. Often times, assistance is necessary to help them read the menu, change the TV channel, find their call light or navigate and access anything in their room. Without a readily available person nearby, their plight becomes an overwhelming challenge. Cognitive impairment, whether mild or severe, places older adults at a distinct disadvantage when they are hospitalized in the realm of physical distancing. Unfamiliar PPE masked personnel and the inability to register and recall the rationale for the change lead to confusion, frustration and an increased risk for poor outcomes including delirium and falls. As the older adult sits alone in their room, fear and anxiety become frequent visitors. What started as a simple admission for a common condition spins out of control into a prolonged hospitalization due to a myriad of complications. And while physical distancing cannot be the sole cause, it certainly provides the fertile ground for unfortunate and unwanted events in older adults.
In an effort to meet the special needs of older adults during this challenging time, providers must go above and beyond for individualized care than limiting to the increased testing capabilities and standard treatment options. This is the moment when providers should adapt core geriatric principles and bridge physical distancing with a HUMAN CONNECTION involving technology assistance and in-room activities designed based on interest and ability. The ability to facetime with families during team rounds, provide audio amplifiers for those challenged by the muffled voices with use of mask and focused in-room activities as puzzle solving, music listening that preserve functionality and emotional balance becomes crucial. This could mean spending an extra few minutes to get to know them as a person, who they are, what they like and what they fear!? This is the hour for goals of care discussions to determine and establish what "QUALITY OF LIFE" means and facilitate appropriate care as needs arise. As the scientific community seeks answers and solutions in the form of research trials, this is the hour when clinicians should not fail to recognize that the older adult patient is a human being-a grandmother, an uncle, a hero to someone else-who has fears, feelings, and worries that they have likely never encountered before. Hence, dear colleagues, as aggressive as our approach to study a trial drug or develop vaccine against the COVID-19, it is time to adapt our care approach and style to demonstrate the human connection and engage the older adult with innovative ideas, despite wearing the PPE and practicing physical distancing.

\section{References}

1. F Zhou, T Yu, R Du, G Fan, Y Liu, et al. (2020) Clinical course and risk factors for mortality of adult inpatients with COVID-19 in Wuhan, China: a retrospective cohort study. Lancet 395(10229):1054-1062.

2. (2020) Older Adults. Centers for Disease Control and Prevention. 